\title{
Survey on Recommendation of Personalized Travel Sequence
}

\author{
Mayuri D. Aswale ${ }^{1}$, Dr. S. C. Dharmadhikari ${ }^{2}$ \\ ME Student, Department of Information Technology, PICT, Pune, India ${ }^{1}$ \\ Head of Department, Department of Information Technology, PICT, Pune, India ${ }^{2}$
}

\begin{abstract}
Now a day, traveling recommendation is important for user who is the plan for traveling. There are many existing techniques which are used for travel recommendation. In this paper explain a personalized travel sequence recommendation system using travelogues and users contributed photos with metadata of this photo by comparing existing different technique. It recommends personalized users travel interest and recommend a sequence of travel interest instead of an individual point of interest. The existing system cannot complete the requirement i.e. personalized and sequential recommendation together. To solve the problem of providing personalized and sequential travel package recommendation, a topical package model is created using social media data in which automatically mine user travel interest with another attribute like time, cost, and season of traveling. The proposed system uses the travelogues and photos of social media which map each user and routes description to the topical package area to induce user topical package model and route topical package model. To suggest personalized POI sequence, first famous routes are stratified as per the similarity between user package and route package. Then high stratified routes are more optimized by using social similar users travel records for more accuracy.
\end{abstract}

Keywords: Travel recommendation, Geo-tagged photos, and Social media.

\section{INTRODUCTION}

In day to day life, people are interested in traveling and searching for the different tourist location for travel planning in which they are interested. Social media has come out continuous needs for automatic travel recommendation. This becomes an important problem in research and industry. Social media offers great opportunities to address many challenging problems, like GPS estimation and travel recommendation. Travelogue websites offer rich descriptions about landmarks and traveling experience written by users. These data are not only useful for reliable POIs i.e. points of interest, travel routes but give an opportunity to recommend personalized travel POIs and routes based on user's interest.

Existing studies on travel recommendation use the different types of social media data, GPS trajectory, check-in-data, geo tag and blogs which are used for mining famous travel POIS and routes [2][4]. The existing system for general travel route planning cannot well meet user's personal requirements. Personalized recommendation of travel system recommends the POIs and routes by mining user's travel history. Location-based collaborative filtering is the most famous method for the recommendation. In this collaborative filtering method, social similar users are mapped based on the location cooccurrence of previously visited POIs. And then POIs are ranked according similar users travel history.

There are two problems in automatic travel recommendation when we compare existing travel recommendation approach. First, the recommended POIs should be personalized to user interest since different users may prefer different types of POIs. Second, it is important to recommend a sequential travel route that is a sequence of POIs rather than individual POI. Existing system on travel recommendation has not well solved the two problems. The first problem, most of the travel recommendation works only focused on user topical interest mining without considering other attributes like consumption capability of the user. And for the second problem, existing studies focused more on famous route mining but not considering user travel interest [1].

To solve the challenges sequential and personalized recommendation of travel location for the user, the new system proposes Topical Package Model method which automatically mines user travel interest from two types of social media data, different user-contributed photos and travelogues. For the first problem, it considers user's topical interest with the attribute like consumption capability and preference of visiting time of user and season. It is difficult to measure the similarity directly between user and route, proposed system build a topical package model and then map both user's and route's textual descriptions to the topical package model to get user topical package model (user package) and route package model (route package) using topical package space[1]. Comparing with existing recommendation system for traveling with this recommendation system is more suited for travel planning for users.

The further paper is organized as follows: Section II review the literature survey for this recommendation 
Vol. 6, Issue 1, January 2017

system. In Section III contain existing system and its disadvantages. Section IV introduces a proposed system for personalized travel recommendation and Section $V$ contains the conclusion and future scope for this recommendation system.

\section{LITERATURE SURVEY}

For travel recommendation system different system uses different types of data to mine user interested POIs, for this mining mainly four kinds of social media data are used that is GPS trajectory, check-in-data, geo tag and blogs for recommendation. User generated travel log provide rich information for a recommendation system.

Liu et al. discovered Areas of Interest by examining geotagged photos and check-ins data simultaneously. In this approach, by combining geo-tagged images and check-ins for the same city, for Area of Interest discovery and ranking those interest, to discover areas in a city in which popular attractive locations and popular locations are located for the travelers. A modified density-based clustering method is used in this approach which devised to identify an area of interest and proposes a novel joint authority analysis framework to the rank area of interest. The proposed framework in this approach simultaneously considers both the location-location transitions, and the user-location relations [5].

S. Jiang, presents an Author topic model-based collaborative filtering method for personalized travel recommendations. Using author topic model user's topic preference can be mined from the textual descriptions attached with user's photos. Through author-topic model, travel topics, and a user's topic preference can be elicited simultaneously. In this recommendation system, POIs are ranked according to similar users, who share similar travel topic preferences. This method overcomes the problem in location-based collaborative filtering, without GPS records, in author-topic model based collaborative filtering method mine similar users accurately according to the similarity of users' topic preferences [2].

J. Sang, explain the potential of location-based service to overcome with an advanced recommendation problem activity plan, which is to suggest a package of sequential activities related to user context and interest. This type of recommendation system of point of interest is a probabilistic approach in which recommended POIs are relevant to user context i.e. current location, time, and check-in and personalized check-in history of the user. This approach of recommendation is highly motivated from a large-scale commercial mobile check-in data analysis, to rank a list of sequential POI categories and different POIs. The approach enables users to plan continuous activities going from one place to another [3].

H. Huang describes collaborative filtering to mine GPS trajectories for providing POI recommendations. Three
Collaborative Filtering methods are designed: simple CF, frequencies $\mathrm{CF}$ which considering visit frequencies of POIs, and frequencies sequence collaborative filtering. This method considers both users' preferences for POI and spatio-temporal behavior. Comparing simple locationbased methods with the collaborative filtering methods, collaborative filtering provides more accurate predictions. It also considers visit frequencies, the popularity of POIs and spatio temporal motion behavior in that which POIs are visited in collaborative filtering can improve the predictive performance [4].

Ge et al. develop a cost aware route recommendation module in which two cost aware latent factor models are developed to recommend travel packages by considering both the travel cost and the tourist's interests and analyze the cost and stay days relation[7].

Q. Yuan studies travel package recommendation which focuses on more Attribute like time, the season of travel. In this travel recommendation the problem of time-aware POI recommendation, this recommends a list of POIs for a user to visit at a given time. To use both geographical and temporal influences in time-aware POI recommendation, proposes the Geographical-Temporal influences Aware Graph to model check-in records, geographical effect and temporal impact [8]. The proposed system recommends personalized travel sequence using social media data. For this recommendation system first mines POI and topical model from photos and travelogue and then route mined according travel history. It mine and rank famous routes based on the similarity between user package module and route package module. For accuracy then the top ranked famous routes optimized according to social similar users travel history for personalized travel sequence recommendation [1].

Xueming Qian explains personalized recommendation which considers two factors, user personal information and users' social group [13]. Subramaniya Swamy described a system which helps to user in finding tourist locations that users want to visit. A place is mined from available user contributed photos of that place available on photo sharing websites. [15]. Q. Liu presents personalized travel recommendation exploiting online travel information.

In this method analyzed the unique characteristics of travel packages and create the Tourist Area Season Topic model, a Bayesian network for travel package and tourist representation [11]. Luepol Pipanmekaporn proposed a novel user-based collaborative POI recommendation algorithm for location-based social networks [16]. This method focuses on inferring user's check-in behaviors from user's location history to make a high-quality recommendation of POIs to a user based on the current location and opinions of similar users [15].

Table 1 shows different techniques for travel recommendation. 
Vol. 6, Issue 1, January 2017

Table 1.Comparative study of different technique

\begin{tabular}{|c|c|c|c|c|c|}
\hline Publication name & Author & $\begin{array}{l}\text { Publication } \\
\text { detail }\end{array}$ & Description & Merits & Limitation \\
\hline $\begin{array}{l}\text { Author Topic Model- } \\
\text { Based Collaborative } \\
\text { Filtering for } \\
\text { Personalized POI } \\
\text { Recommendations. }\end{array}$ & $\begin{array}{l}\text { S. Jiang, X. } \\
\text { Qian, J. Shen, } \\
\text { Y. Fu, and T. } \\
\text { Mei }\end{array}$ & $\begin{array}{l}\text { IEEE } \\
\text { Trans.Multim } \\
\text { edia, vol. 17, } \\
\text { no. 6, pp. } \\
\text { 907-918, Jun. } \\
2015\end{array}$ & $\begin{array}{l}\text { This method makes } \\
\text { possible } \\
\text { comprehensive points } \\
\text { of interest } \\
\text { recommendations for } \\
\text { social users. User } \\
\text { preference topics are } \\
\text { extracted from the geo- } \\
\text { tag constrained textual } \\
\text { description of photos } \\
\text { via the author topic } \\
\text { model. }\end{array}$ & $\begin{array}{l}\text { Without GPS } \\
\text { records, similar } \\
\text { users can still be } \\
\text { mined accurately } \\
\text { according to the } \\
\text { similarity } \\
\text { users' of } \\
\text { preferences. }\end{array}$ & $\begin{array}{l}\text { Data would be } \\
\text { even sparser and } \\
\text { noisier. }\end{array}$ \\
\hline $\begin{array}{l}\text { GPS Estimation for } \\
\text { Places of Interest } \\
\text { From Social Users' } \\
\text { Uploaded Photos. }\end{array}$ & $\begin{array}{l}\text { J. Li, X. Qian, } \\
\text { Y. Y. Tang, L. } \\
\text { Yang, and T. } \\
\text { Mei, }\end{array}$ & $\begin{array}{l}\text { IEEE Trans. } \\
\text { Multimedia, } \\
\text { vol. 15, no. 8, } \\
\text { pp. 2058- } \\
2071, \quad \text { Dec. } \\
2013 .\end{array}$ & $\begin{array}{l}\text { It proposes a system of } \\
\text { hierarchical structure } \\
\text { to estimate the GPS } \\
\text { location for an image } \\
\text { with hierarchical } \\
\text { global feature } \\
\text { clustering and local } \\
\text { feature refinement. }\end{array}$ & $\begin{array}{l}\text { Save } \\
\text { computational } \\
\text { costs and } \\
\text { improve the GPS } \\
\text { estimation } \\
\text { accuracy. }\end{array}$ & $\begin{array}{l}\text { Challenging to } \\
\text { estimate image } \\
\text { GPS for photos. }\end{array}$ \\
\hline $\begin{array}{l}\text { Probabilistic } \\
\text { Sequential POIs } \\
\text { Recommendation via } \\
\text { Check-In Data. }\end{array}$ & $\begin{array}{l}\text { J. Sang, T. } \\
\text { Mei, T. J. Sun, } \\
\text { S. Li, and C. } \\
\text { Xu }\end{array}$ & $\begin{array}{l}\text { ACM } \\
\text { SIGSPATIAL } \\
\text { Int. Conf. } \\
\text { Adv. } \\
\text { Geographic } \\
\text { Inform. Syst., } \\
2012 \text {, pp. } \\
402-405 .\end{array}$ & $\begin{array}{l}\text { It explores the } \\
\text { potential of location- } \\
\text { based service, which is } \\
\text { to suggest a package of } \\
\text { sequential activities } \\
\text { related to user context } \\
\text { and interest. }\end{array}$ & $\begin{array}{l}\text { Significance in } \\
\text { recommending } \\
\text { sequential } \\
\text { activities. }\end{array}$ & $\begin{array}{l}\text { It not } \\
\text { considering } \\
\text { longer check-in } \\
\text { sessions }\end{array}$ \\
\hline $\begin{array}{l}\text { Using trajectories for } \\
\text { collaborative } \\
\text { filtering-based POI } \\
\text { Recommendation. }\end{array}$ & $\begin{array}{l}\text { H. Huang and } \\
\text { G. Gartner }\end{array}$ & $\begin{array}{l}\text { Int. J. Data } \\
\text { Mining, } \\
\text { Modelling } \\
\text { Manage., vol. } \\
\text { 6, no. 4, pp. } \\
\text { 333-346, } \\
2014 .\end{array}$ & $\begin{array}{lr}\text { Collaborative } & \text { filtering } \\
\text { to mine } & \text { GPS } \\
\text { trajectories } & \text { for } \\
\text { providing Amazon-like } \\
\text { POI recommendations. }\end{array}$ & $\begin{array}{l}\text { More accurate } \\
\text { recommendation } \\
\text { compare with } \\
\text { simple location- } \\
\text { based methods. }\end{array}$ & \\
\hline $\begin{array}{l}\text { Automatic generation } \\
\text { of multimedia tour } \\
\text { guide from local } \\
\text { blogs. }\end{array}$ & $\begin{array}{l}\text { H. Kori, S. } \\
\text { Hattori, } \text { T. } \\
\text { Tezuka, and } \\
\text { K. Tanaka }\end{array}$ & $\begin{array}{l}\text { Adv. } \\
\text { Multimedia } \\
\text { Model.,vol. } \\
\text { 4351, no. 1, } \\
\text { pp. 690-699, } \\
2006\end{array}$ & $\begin{array}{l}\text { It describe a system } \\
\text { that extracts typical } \\
\text { visitor's travel routes } \\
\text { based on blog entries } \\
\text { and that presents } \\
\text { multimedia content } \\
\text { relevant to those } \\
\text { routes. A sequential } \\
\text { pattern mining method } \\
\text { is used for route } \\
\text { extraction. }\end{array}$ & $\begin{array}{l}\text { Using desktop or } \\
\text { a mobile device } \\
\text { its act like tour } \\
\text { guide. }\end{array}$ & \\
\hline $\begin{array}{l}\text { W2Go: A Travel } \\
\text { Guidance System by } \\
\text { Automatic Landmark } \\
\text { Ranking }\end{array}$ & $\begin{array}{l}\text { Y. Gao, J. } \\
\text { Tang, R. } \\
\text { Hong, Q. Dai, } \\
\text { T. Chua, and } \\
\text { R. Jain, }\end{array}$ & $\begin{array}{l}\text { Int.Conf. } \\
\text { Multimedia, } \\
2010, \quad \text { pp. } \\
123-132\end{array}$ & $\begin{array}{l}\text { It } \\
\text { recognizes and ranks } \\
\text { the landmarks for } \\
\text { travellers. In this } \\
\text { system, a novel } \\
\text { Automatic Landmark } \\
\text { Ranking method is } \\
\text { explained by utilizing }\end{array}$ & $\begin{array}{l}\text { The system } \\
\text { provides effective } \\
\text { assistance to } \\
\text { travellers. }\end{array}$ & $\begin{array}{l}\text { It is hard to } \\
\text { remove tags of } \\
\text { events and } \\
\text { activities from } \\
\text { the landmark list } \\
\text { as they are } \\
\text { location- } \\
\text { sensitive. }\end{array}$ \\
\hline
\end{tabular}


Vol. 6, Issue 1, January 2017

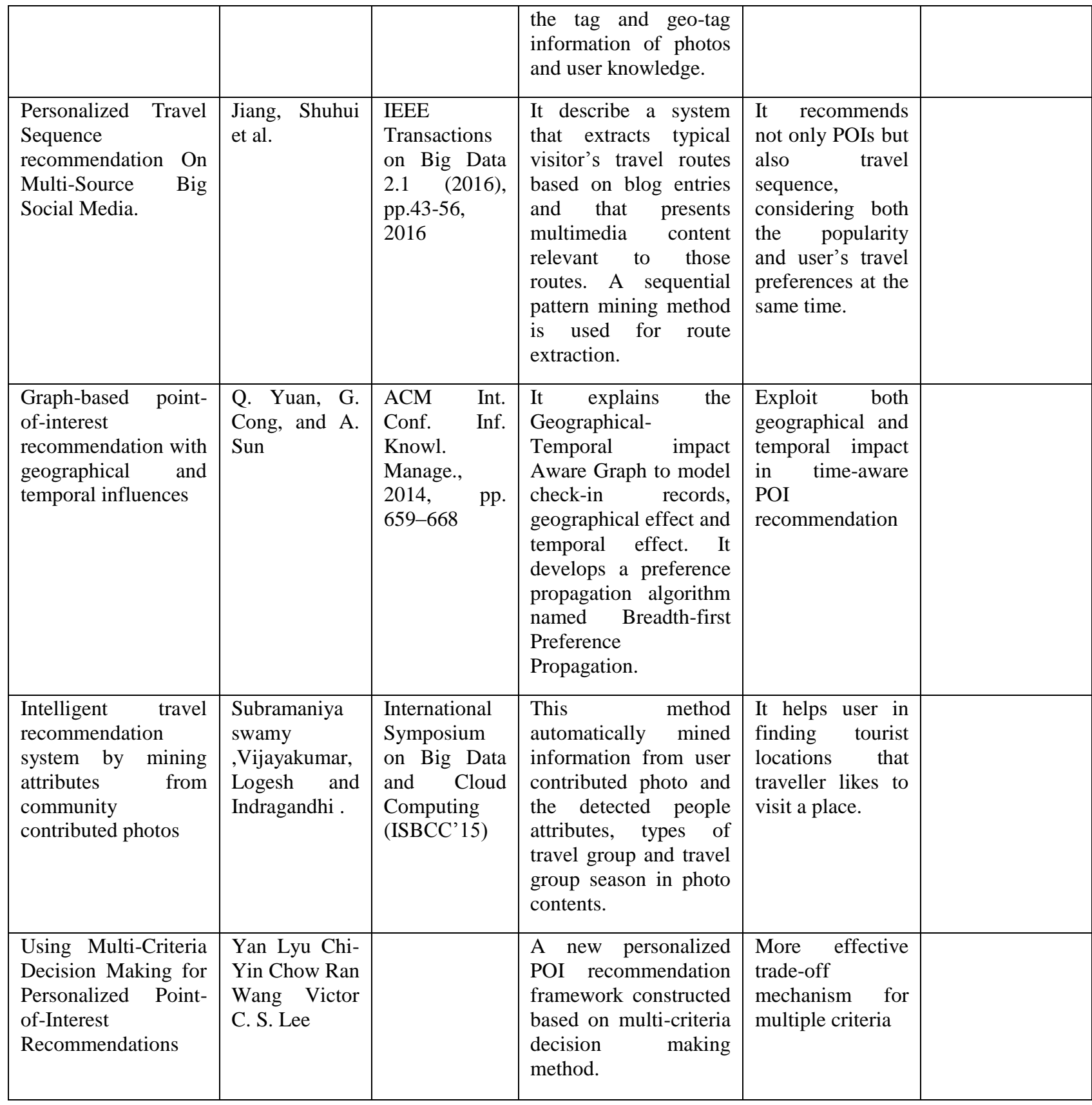

\section{III.EXISTING SYSTEM}

The existing system for travel recommendation uses different techniques for travel recommendation but did not consider popularity and personalization of travel route at the same time. Collaborative filtering is the most popular method for the recommendation. Location based collaborative filtering method for recommendation method considers only popular route location for recommendation [2]. The point of interest mining for recommendation is done in the existing system without considering users attribute like time, cost, season which is not mined automatically.

For travel recommendation in existing system data mined recommendation works only focused on user topical from different kinds of data contained on social media interest mining but not consider other attributes like 
Vol. 6, Issue 1, January 2017

consumption capability of different users. For the second Modules:

problem existing studies focused more on famous route mining but not automatically mining user travel interest. It still remains difficult for existing travel recommendation system to provide personalized and sequential travel recommendation. The existing system cannot give personalized recommendation to the user with the sequence of POI.

\section{Disadvantages of Existing System:}

The existing studies related to travel sequence recommendation did not well consider the popularity and personalization of travel routes at the same time.

The multi-attributes of users and routes e.g., consumption capability, preferred season, etc. have not been mined automatically.

\section{PROPOSED SCHEME}

To solve the problem of the existing system for travel recommendation, this paper explains a Topical Package Model learning method to automatically mine user travel interest from two types social media data of traveling, users uploaded photos of traveling and travelogues i.e. user experience. This system overcomes the disadvantage of an existing system.

This system considers user's topical interest and the attribute like cost, time and season of travel of user prefer and preference of visiting time and season of users. It is difficult to measure the similarity between user and route for travel, for this create a topical package model by mining travel-log and users uploaded photos. And compare both user's and route's textual descriptions to the topical package model to get user topical package model and route topical package model using topical package space. Map route module and user module to get recommendation results. To create the topical module the user's photo collection is divided into trip groups. Example photos and representative tags are displayed in recommendation module. Following fig4.1 shows the proposed system architecture for a recommendation.

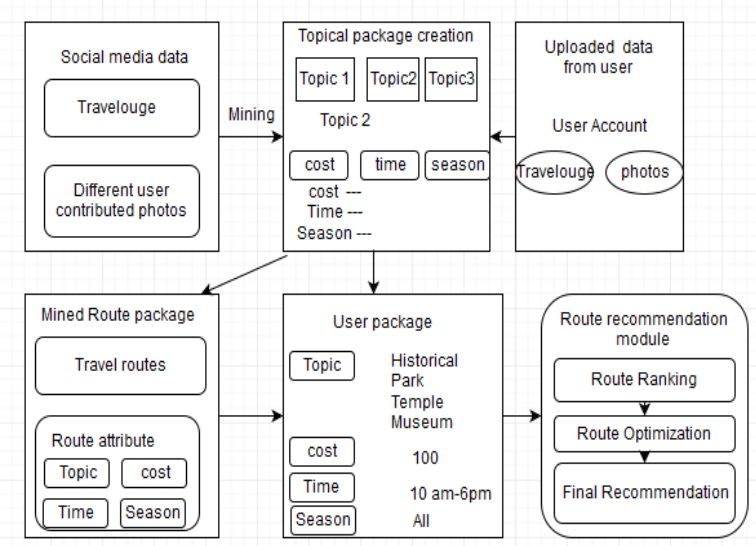

Fig.1 System architecture for route recommendation system [1].
In this paper proposed system contain topical package space module, user route module, route package module and recommendation module.

Topical package module construction first mines the travelogue and photos to identified point of interest, also mine the metadata about POI. This module contains travel distribution of topics with its attribute i.e. mine travelogue which describes POI within the same topic, the consumer expenditure, distribution of season, and preferred visiting time. From the topical package module, construct route package module which gives information about a route includes route cost, time and season for route.

User package module which constructs from topical package space by mapping user photos to topical package space. It contains user interested topic, preferred time of user and season.

Route module constructs by mapping travelogue related to the POI to topical package module. It contains a route of topical interest, cost distribution for route, time and season distribution for a route.

Route recommendation module constructs in two steps to recommends personalized route sequence to user. Step contain first route ranking and then route is optimized by similar user history for more accuracy. For route ranking process, route is ranked according to the similarity between user package and route package module. In route optimization process set of ranked route optimized according to social similar users records.

\section{CONCLUSION AND FUTURE WORK}

This paper explain a recommendation system for personalized travel sequence in which recommendation is based on two types of social media data, travelogues written by users and users contributed photos on social media. This recommendation system considers the user interest with another attribute of users like time, season, and cost of travel. Using this social media data not only mining users point of interest but also the travel sequence of the point of interest with considering other attribute of user i.e. consumption capability of the user. For future work, we can use more type of data for mining user interest and can provide information for a recommendation like hotel information and transportation detail for the user for convenience tour planning.

\section{REFERENCES}

[1] Jiang, Shuhui et al. "Personalized Travel Sequence Recommendation on Multi-Source Big Social Media". IEEE Transactions on Big Data 2.1 (2016), pp.43-56, 2016

[2] S. Jiang, X. Qian, J. Shen, Y. Fu, and T. Mei, "Author topic model based collaborative filtering for personalized POI recommendation," IEEE Trans.Multimedia, vol. 17, no. 6, pp. 907918, Jun. 2015.

[3] J. Sang, T. Mei, J.-T. Sun, C. Xu, and S. Li, "Probabilistic sequential POIs recommendation via check-in data," in Proc. 20th Int. Conf. Adv.Geographic Inf. Syst., 2012, pp. 402-405. 
[4] H. Huang and G. Gartner, "Using trajectories for collaborative filtering-based POI recommendation," Int. J. Data Mining, Modelling Manage., vol. 6, no. 4, pp. 333-346, 2014.

[5] J. Liu, Z. Huang, L. Chen, H. T. Shen, and Z. Yan, "Discovering areas of interest with geo-tagged images and check-ins," in Proc. 20th ACM Int. Conf. Multimedia, 2012, pp. 589-598.

[6] S. Jiang, X. Qian, J. Shen, and T. Mei, "Travel recommendation via author topic model based collaborative filtering," in Proc. 21st Int. Conf., MMM 2015, Sydney, N.S.W., Australia, 2015, pp. 392-402.

[7] Y. Ge, Q. Liu, H. Xiong, A. Tuzhilin, and J. Chen, "Cost-aware travel tour recommendation," in Proc. 17th ACM Int. Conf. Knowl. Discovery Data Mining, 2011, pp. 983-991

[8] Q. Yuan, G. Cong, and A. Sun, "Graph-based point-of-interest recommendation with geographical and temporal influences," in Proc. 23rd ACM Int. Conf. Inform. Knowl. Manage, 2014, pp. 659668.

[9] Y. Gao, J. Tang, R. Hong, Q. Dai, T. Chua, and R. Jain, "W2go: A travel guidance system by automatic landmark ranking," in Proc. Int.Conf. Multimedia, 2010, pp. 123-132

[10] H. Kori, S. Hattori, T. Tezuka, and K. Tanaka, "Automatic generation of multimedia tour guide from local blogs," Adv. Multimedia Model.,vol. 4351, no. 1, pp. 690-699, 2006.

[11] Q. Liu, Y. Ge, Z. Li, E. Chen, and H. Xiong, "Personalized travel package recommendation," in Proc. IEEE 11th Int. Conf. Data Mining, 2011, pp. 407-416.

[12] X. Wang, M. Yu, L. Zhang, R. Cai, and W. Ma, "Argo: Intelligent advertising by mining a user's interest from his photo collections," in Proc. 3rd Int. Workshop Data Mining Audience Intell. Advertising, 2009, pp. 18-26.

[13] X. Qian, H. Feng, G. Zhao, and T. Mei, "Personalized recommendation combining user interest and social circle," IEEE Trans. Knowl. Data Eng., vol. 26, no. 7, pp. 1763-1777, Jul. 2014.

[14] Q. Hao, R. Cai, X. Wang, J. Yang, Y. Pang, and L. Zhang, "Generating location overviews with images and tags by mining user-generated travelogues," in Proc. 17th ACM Int. Conf. Multimedia, 2009, pp. 801-804

[15] V. Subramaniyaswamy, V. Vijayakumar, R. Logesh and V. Indragandhi, "Intelligent Travel Recommendation System by Mining Attributes from Community Contributed Photos", Procedia Computer Science, vol. 50, pp. 447-455, 2015.

[16] L. Pipanmekaporn and S. kamolsantiroj, "Mining Semantic Location History for Collaborative POI Recommendation in Online Social Networks", 2016 2nd International Conference on Open and Big Data (OBD), 2016.

\section{BIOGRAPHIES}

Mayuri D. Aswale, received $\mathrm{BE}$ degree in computer Engineering, from BAMU University, Aurangabad in 2014. She is currently pursuing ME Degree in Department of Information Technology from Pune Institute of computer technology, Pune. Her area of interest includes data mining.

Dr. S. C. Dharmadhikari, Head of Information Technology Department, Pune Institute of Computer Technology, Pune. She has received M.E. degree in Computer Engineering from Bharati Vidhyapeeth, Pune and completed Ph.D in computer from Devi Ahilya Vishwa Vidyalaya, Indore. Her research interest is Machine learning, Data Mining and System Programming. 